\title{
The Effect of Family-centered Empowerment on Quality of Life in Children with Hemophilia
}

\author{
Shahnaz Rostami' ${ }^{1}$, Soulmaz Namaki Khameneh ${ }^{2}$, Bijan Keikhaei Dehdezi ${ }^{3}$, \\ Mohammad Hossein Haghighizadeh*4
}

1. Assistant Professor, Department of Nursing and Midwifery, School of Nursing and Midwifery, Ahvaz Jundishapur University of Medical Sciences, Ahvaz, Iran

2. Nursing Student, Department of Nursing and Midwifery, School of Nursing and Midwifery, Ahvaz Jundishapur University of Medical Sciences, Ahvaz, Iran

3. Professor, Thalassemia \& Hemoglobinopathy Research Center, Ahvaz Jondishapur University of Medical Sciences, Ahvaz, Iran

4. M.Sc., Department of Statistics and Epidemiology, Jundishapur University of Medical Sciences, Ahvaz, Iran

\begin{tabular}{|c|c|}
\hline Article Info & ABSTRACT \\
\hline $\begin{array}{l}\text { Received: 2019/06/08; } \\
\text { Accepted: 2019/09/11; } \\
\text { Published Online: 2020/01/03 }\end{array}$ & $\begin{array}{l}\text { Introduction: Quality of life is one of the influencing factors in children with } \\
\text { hemophilia. The quality of life of children with hemophilia is affected by complaints } \\
\text { of permanent pain, bleeding, and discomfort related to treatment complications. The } \\
\text { aim of this study was to determine the effect of family-centered empowerment on } \\
\text { quality of life of children with hemophilia in Ahvaz city in year } 2018 \text {. }\end{array}$ \\
\hline
\end{tabular}

$\underline{10.30699 / a j n m c .28 .1 .1}$

Original Article

Use your device to scan and read the article online

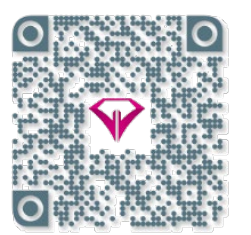

Methods: In this quasi-experimental study, 50 children with hemophilia who referred to hematology clinic of Baqaei Hospital, Ahwaz, Iran, were randomly selected. The experimental group received 9 training sessions based on the familycentered empowerment model comprising four steps of threat perception, problem solving, educational participation and evaluation by the researcher with the presence of primary caregivers and children with hemophilia. The control group received only the routine care program. At baseline and one month after the intervention, both groups completed the demographic and quality of life questionnaire for hemophilic children. Data were analyzed using descriptive and inferential statistics (independent t-test, paired t-test, Fisher exact test, and Chi-square test) using SPSS 22.

Results: The study showed no significant difference in total score of quality of life in children $(P=0.444)$ before intervention between the two groups; but after the intervention a significant difference was observed in terms of quality of life $(P=0.030)$ and family dimension $(P=0.019)$, friends $(P=0.015)$ and perceived support $(P=0.011)$ between the two groups.

Conclusion: According to the results of this study, it can be said that familycentered empowerment can be used as a low cost and easy way to improve the quality of life of hemophilia patients by nurses.

Keywords: Family empowerment, Quality of life, Hemophilia, Child

\section{How to Cite This Article:}

Rostami S, Namaki KHameneh S, Keikhaei Dehdezi B, Haghighizadeh M H. The Effect of Familycentered Empowerment on Quality of Life in Children with Hemophilia. Avicenna J Nurs Midwifery care. $2020 ; 28(1): 1-10$ 


\section{بررسى تأثير توانمندسازى خانوادهمحور بر كيفيت زندكى كودكان مبتلابه هموفيلى}

\section{شهناز رستمى'، سولماز نمكى خامنه '، بيزن كيخايى دهدزى"، محمدحسين حقيقىزاده}

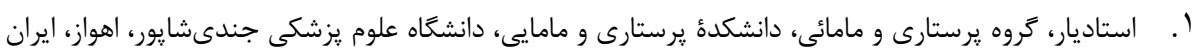

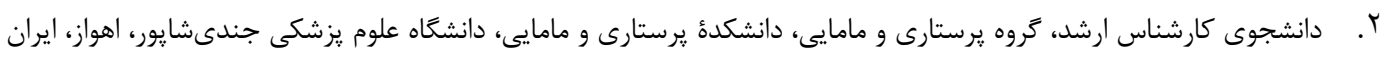

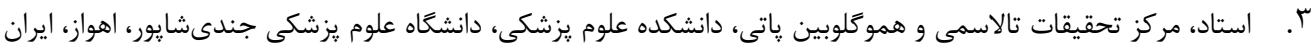

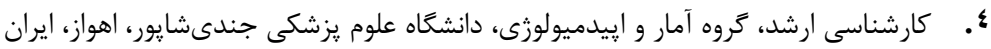

\begin{tabular}{|c|c|}
\hline جكيده & اطلاعات مقاله \\
\hline 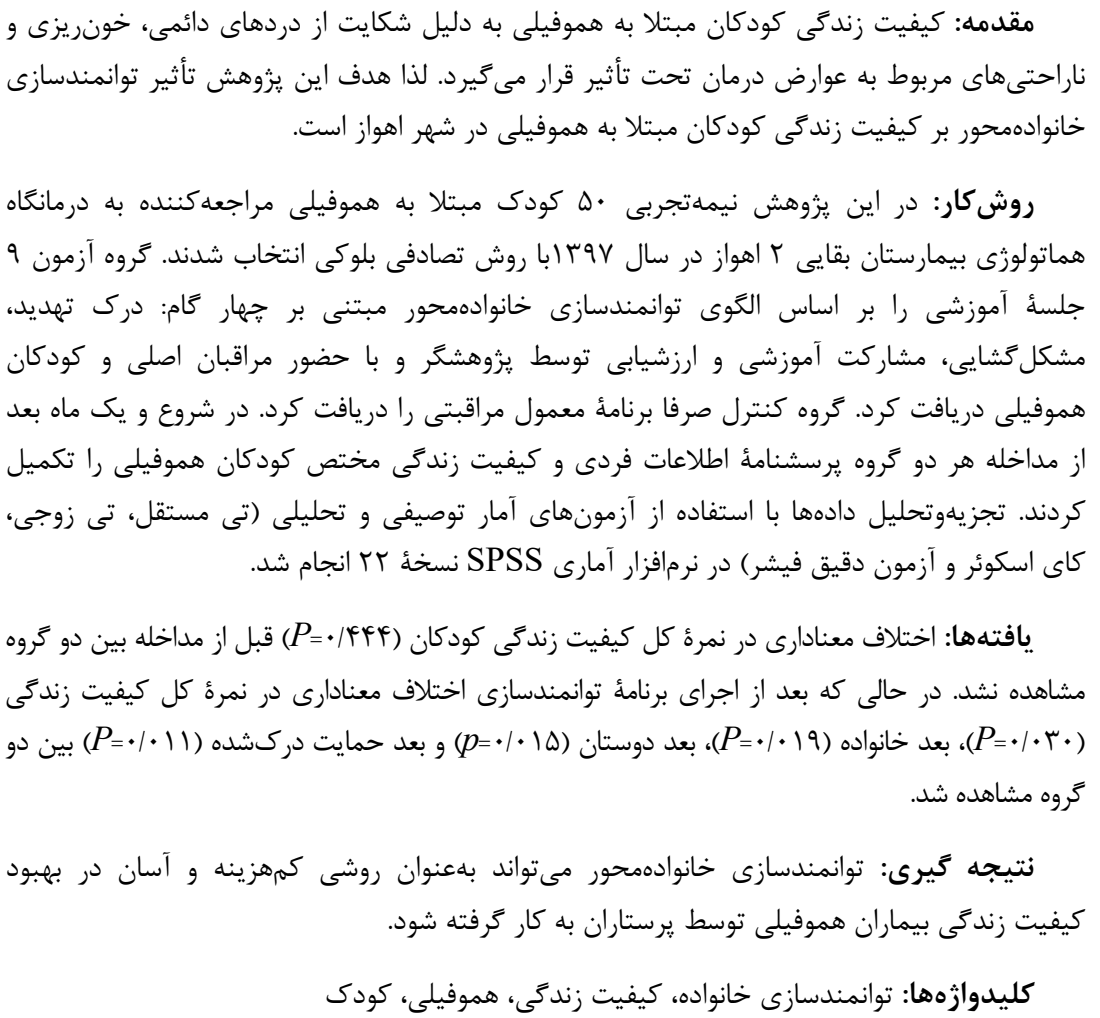 & 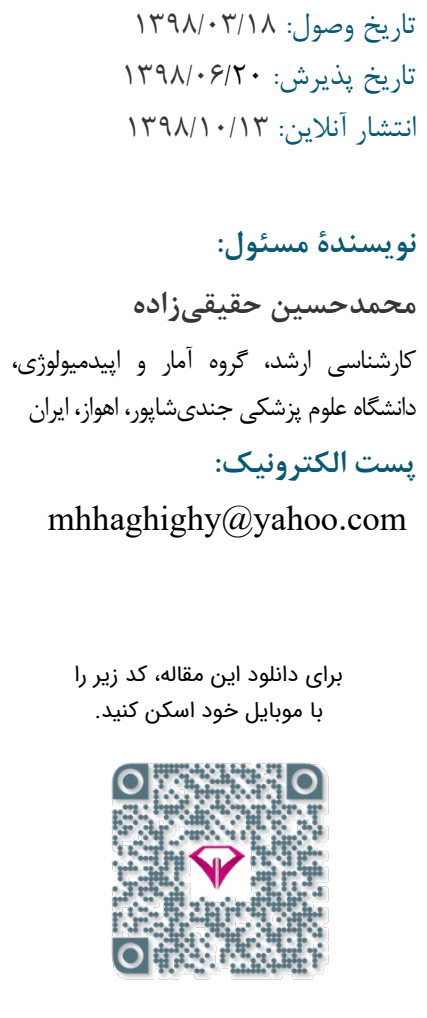 \\
\hline
\end{tabular}

مقدمه

يكى از عوامل متأثر از بيمارى در كودكان مبتلا به هموفيلى

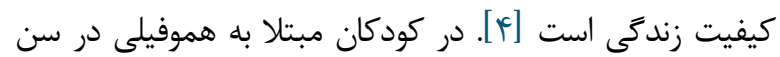

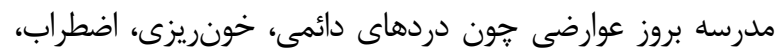

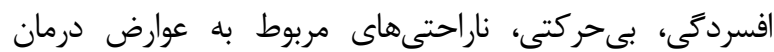

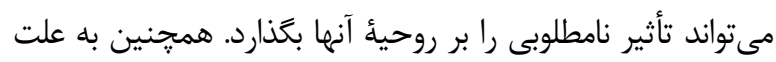

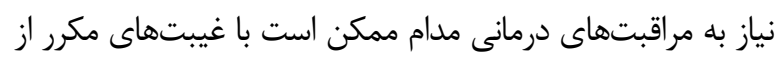

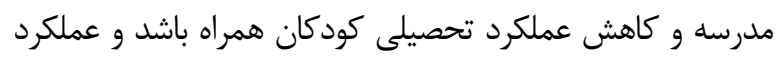

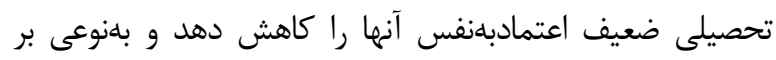

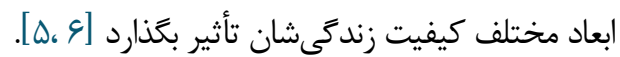

هموفيلى شايعترين اختلال خونريزىدهندة ارثى و سومين

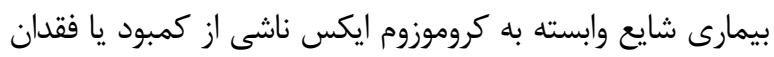

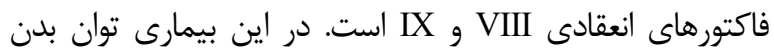

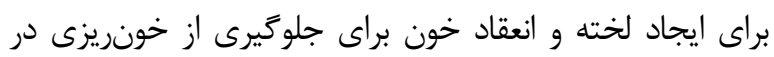

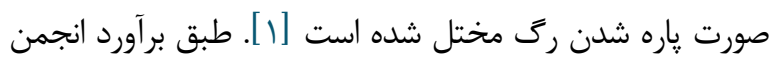

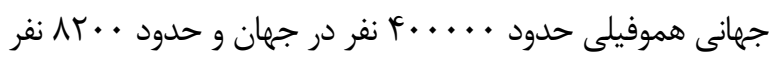

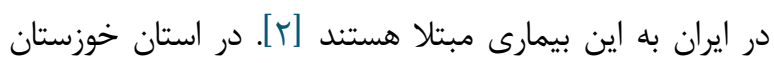

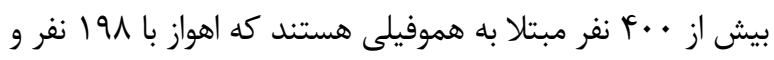
دزفول با ب ـا نفر بيشترين ميزان هموفيلى را دارند [ب]]. 


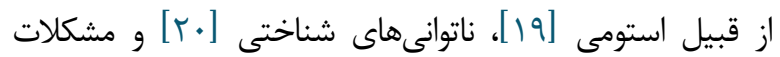

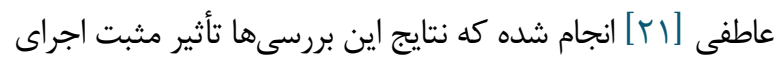

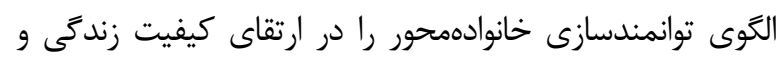

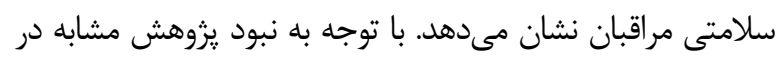

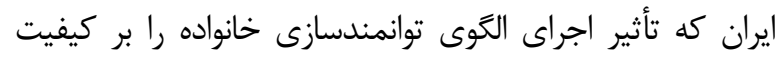

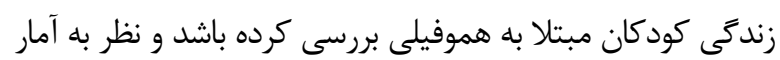

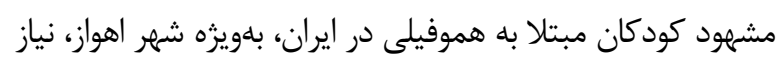

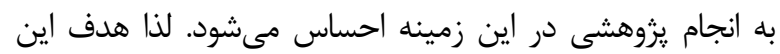

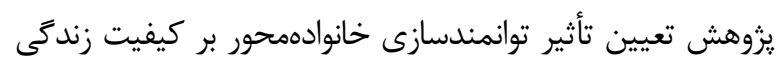

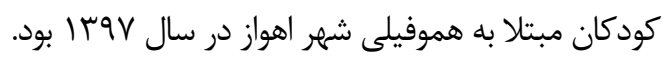

\section{روش بررسى \\ شر كت كنندكان}

اين يزوهش نيمهتجربى با گروه كنترل در دريند درمانئاه

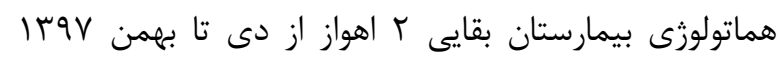

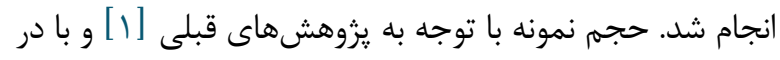
نظر كرفتن ه./

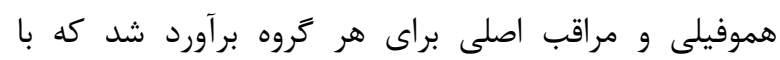

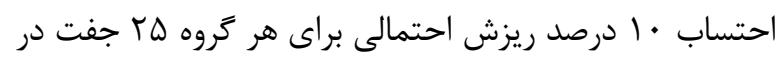

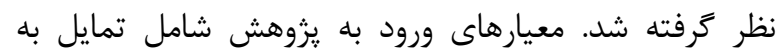
شركت در يزوهش، تشخيص بيمارى كودى مبتلا به هموفيلى نوع A A B توسط يزشك و داشتن يرونده در درمانعاه

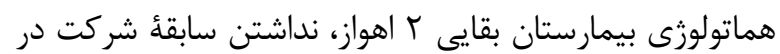

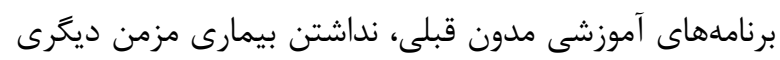

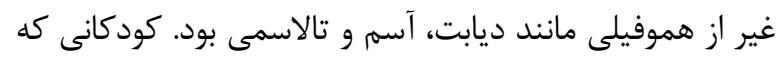

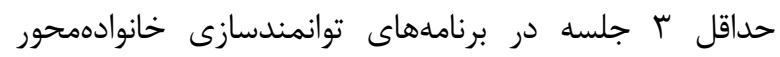

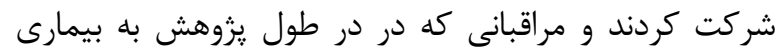

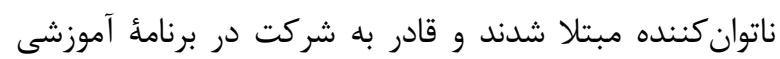

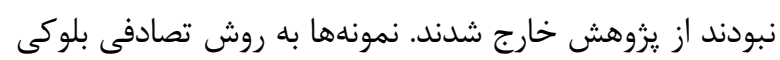

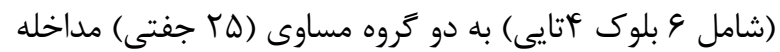

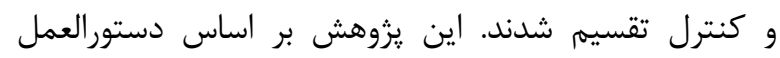
منتشرشده در بيانئ هلسينكى انجام شد. مجوز لازئ لازم از كميته

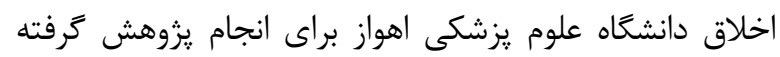

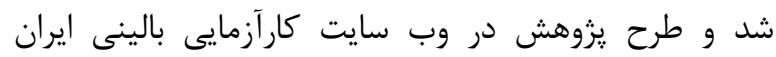

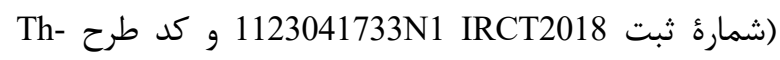
9710 ثبت شد. قبل از نمونه كيرى از همأ شركت كنندكان در

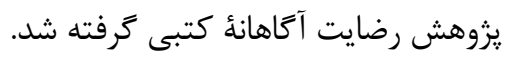

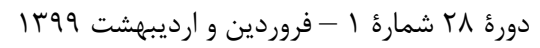

يزوهشهاى متعدد نشان مىدهد كه كيفيت زندگى بيماران

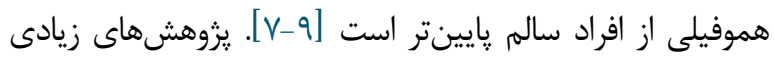

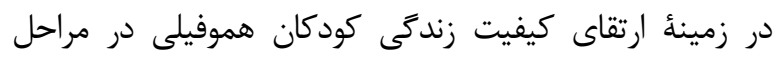

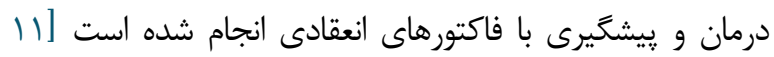

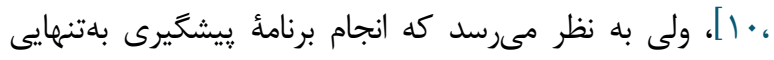

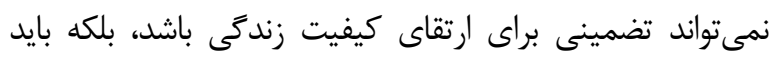

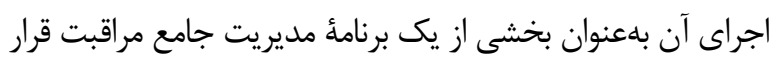

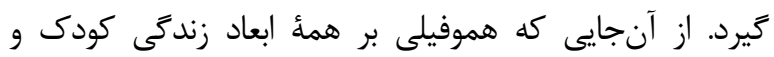

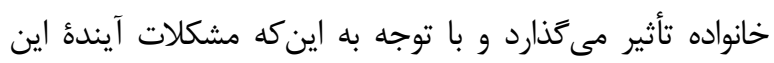

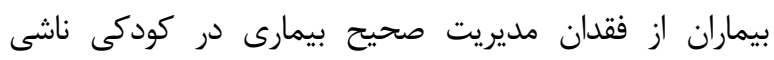

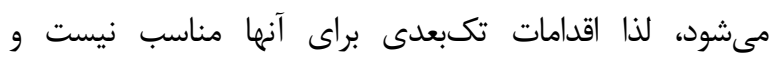

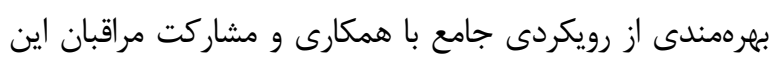

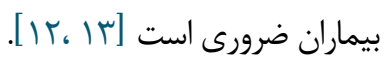

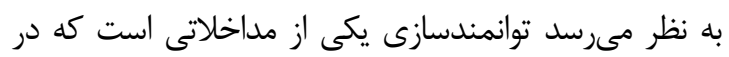

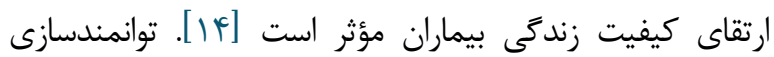

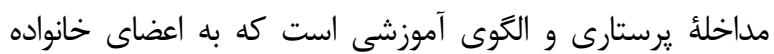

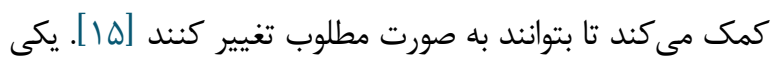

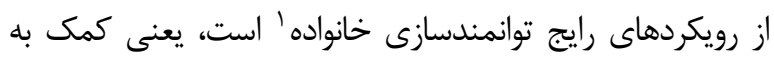

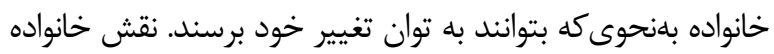

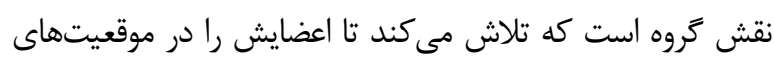

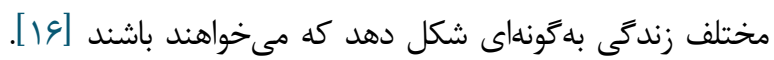

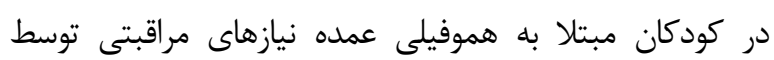

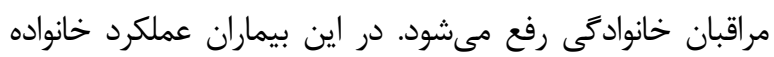

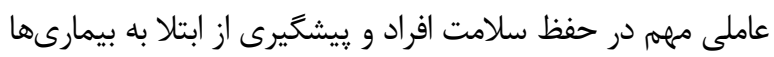

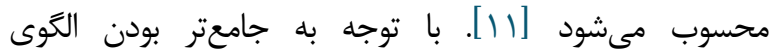

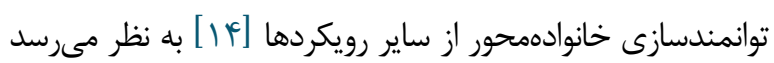

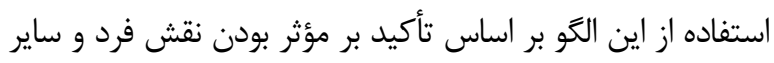
اعضاى خانواده در سه حيطة شناختى، عملكردى و روانى مؤثرتر

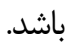
و توانمندسازى خانواده را عامل افزايش اميد به زندگى Nazari

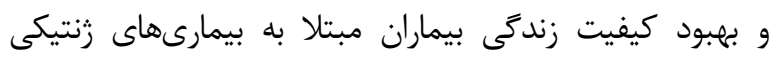

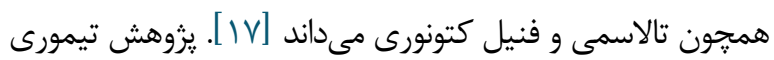

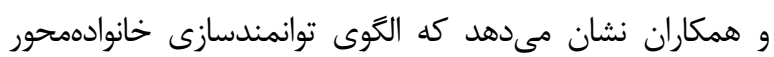

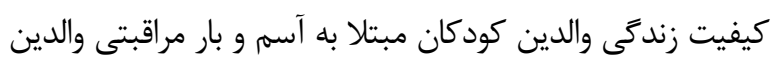

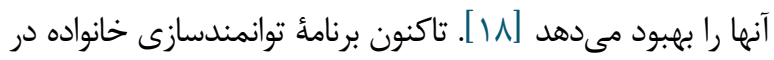

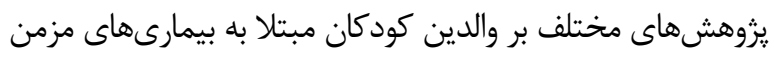

\section{${ }^{1}$ Family empowerment}

مجله مراقبت يُرستارى و مامايى ابنسينا 
كنترل و ييشخيرى، بررسى بهبود رفتارهاى خودمراقبتى)، ارائٔ راهحلها (بحث، بررسى و يافتن بهترين راهحل براى افزايش بردي

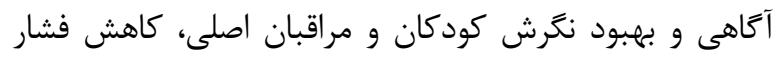

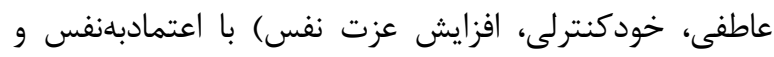
احساس اينكه من مىتوانم در وضعيتم نقش داشته باشم در

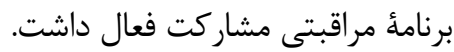

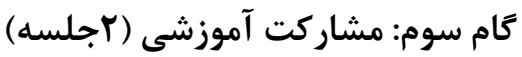

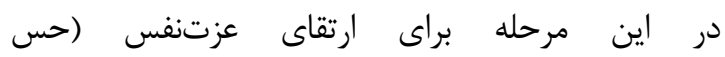

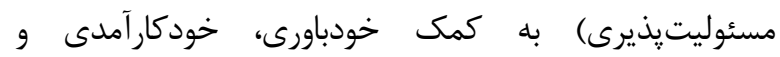
خودكنترلى به روش مشاركت آموزشى از مراقبان اصلى

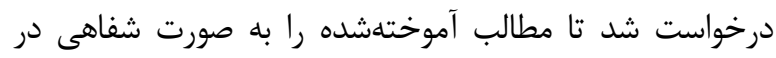
جلسه يادآورى كنند. همجنين در اين مرحله يمفلت و كتاب

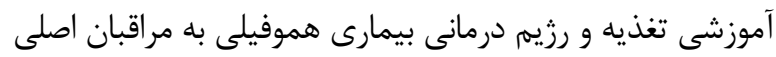

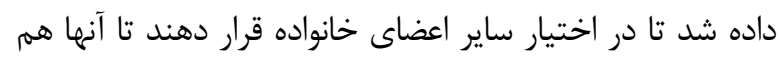

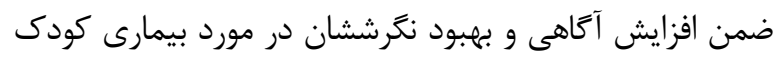
در فرايند كاهش بار مراقبتى مراقبان شركت كنند. با توجه به

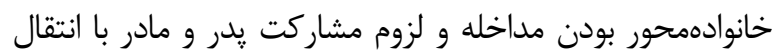

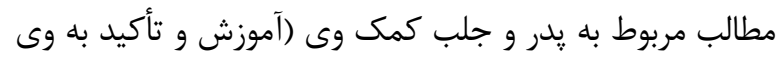
براى حضور منظم و مدام در بيمارستان براى درياف إنداف

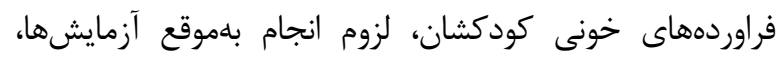

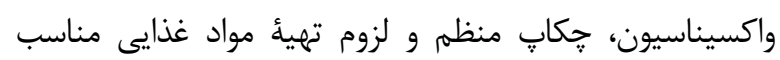
براى كودى) مىتواند وى را در اين كار وارد كند.

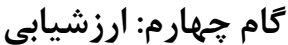

ارزشيابى در دو مرحلة ارزشيابى فرايند و ارزشيابى نهايى

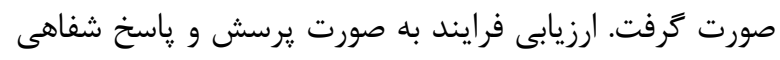

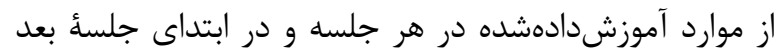
است و ارزشيابى نهايى با تكميل مجدد ابزارها بعد از مداخله

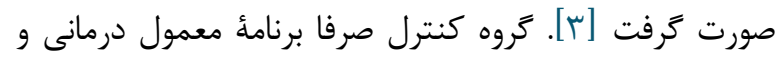

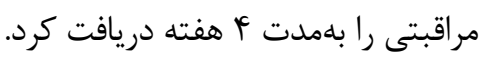

\section{بر رسى متغيرها}

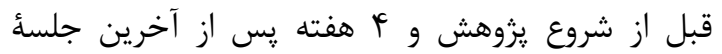

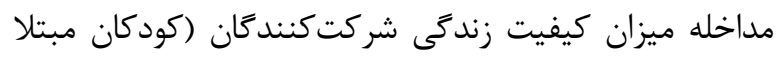

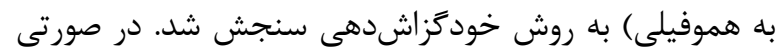

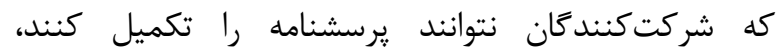

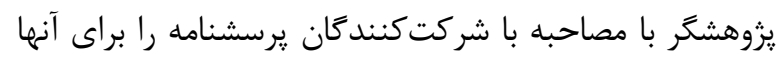

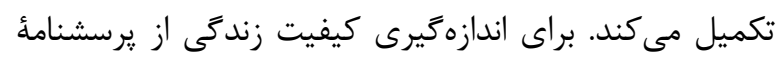
اختصاصى سنجش كيفيت زندگى كودكان مبتلا به هموفيلى

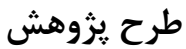

افراد گروه مداخله علاوه بر دريافت مراقبتهاى معمول

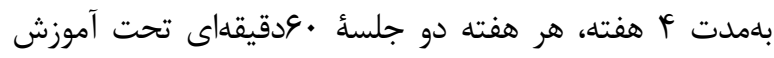

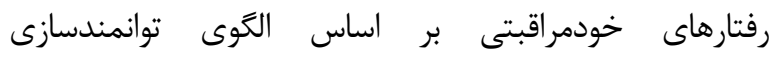
خانوادهمحور قرار كرفتند. اين الكو در سال ب...r توسط Alhani خانوادمدحور مبتنى بر جهار كام درك تهديد، مشكل

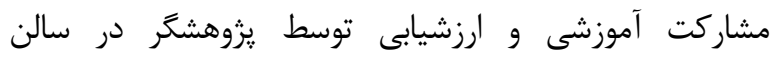
كنفرانس بيمارستان با حضور مراقبان اصلى و كودكان مبتلا به هموفيلى اجرا شد. اين جلسات به صورت جهرهبهجرهره همراه بان بان

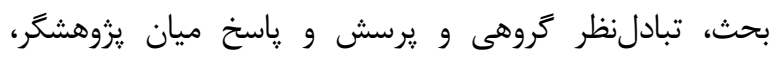
مراقبان اصلى و كودكان همراه با نمايش اسلايد و فيلم و ارائئ

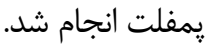
اين الكو شامل جهار كام است: كام اول: درك تهديد ـ حساسيت دركشده (r جلسه) و شدت دركشده ( إنلسه)

\section{الف. حساسيت دركشده}

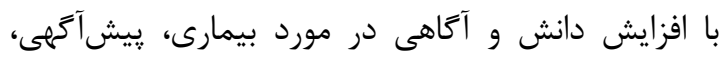

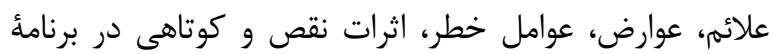
درمان به شيوه بحث كروهى توضيح داده شد. براى جلوكيرى از فراموشى بين تشكيل جلسات تماسهاى بيگيرى تلفنى با بان مراقبان برقرار شد. ب. شدت دركشده روشهاى ييشخيرى و كنترل بيمارى هموفيلى، انجام رفتارهاى صحيح (حفظ دقيق و متعادل رزيم غذايى، رزيم

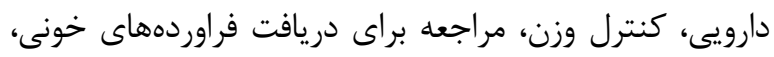

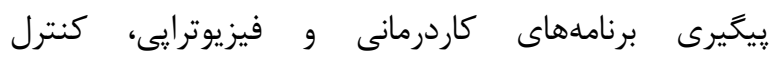
خونريزىهاى احتمالى و لزوم انجام مشاوره زنتيك) و اهميت

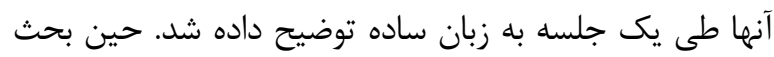

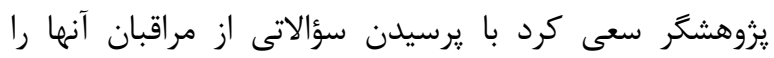
تشويق به مشاركت در بحث كند و مطالب را با توجه به نياز و و سطح درك آنها توضيح دهد.

\section{كام دوم: مشكل آششايى (آجلسه)}

بر اساس مراحل مشكل

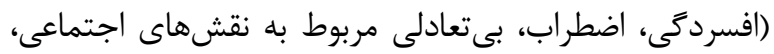

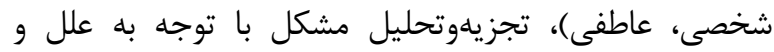

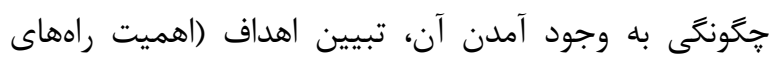


همجنين روايى صورى ابزار بر ه كودى مبتلا به هموفيلى

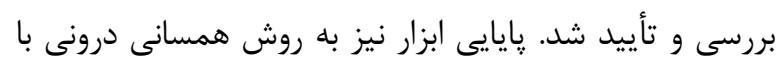

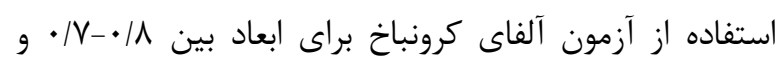

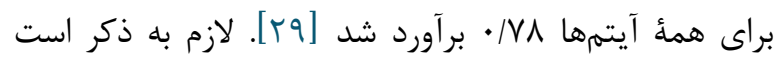

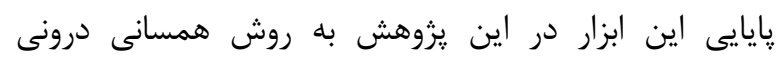

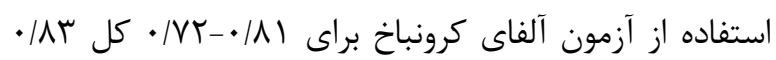

محاسبه شد.

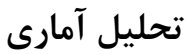

براى بررسى نرمال بودن توزيع متغيرها از آزمون

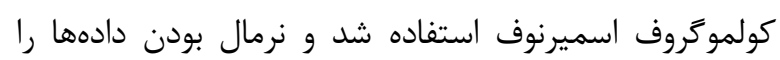

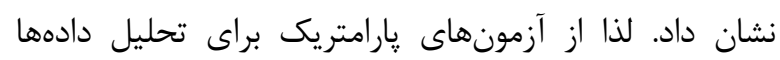

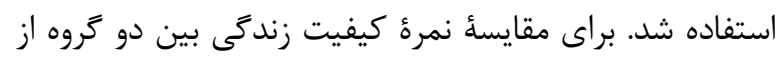

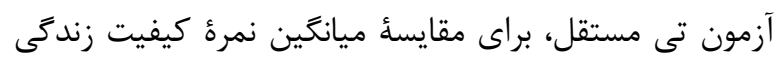

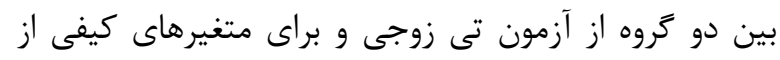

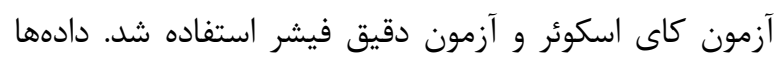

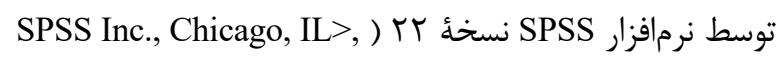
تجزيهوتحليل شد. در همأ موارد سطح معنادارى هـ هـ (USA در نظر كرفته شد.

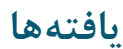

در اين يزوهش •له نمونه در دو كروه مداخله (لى نفر ) و

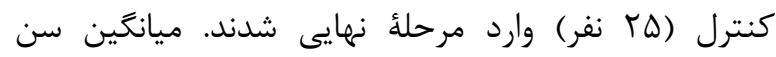

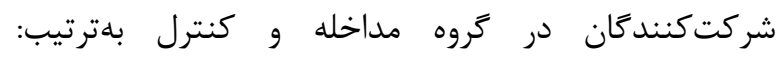
ك

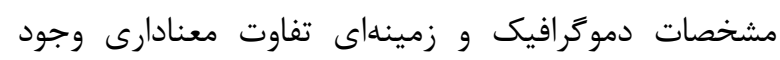

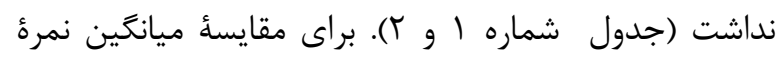

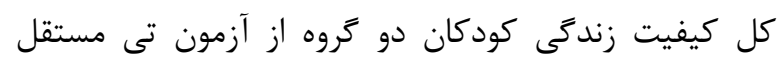

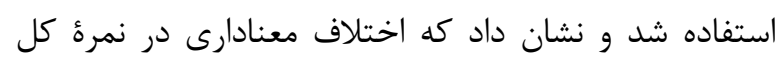

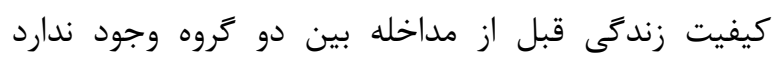
(P=)/D9V)

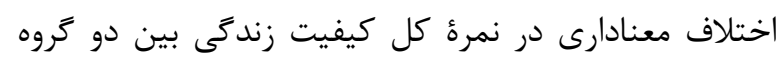

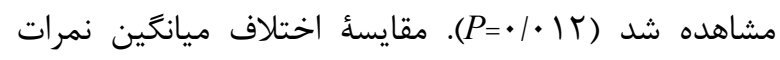

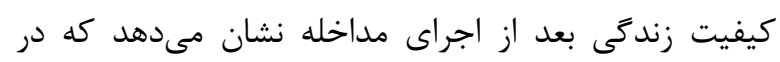

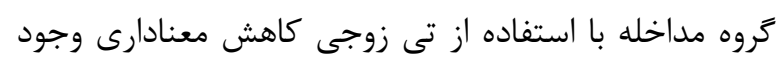

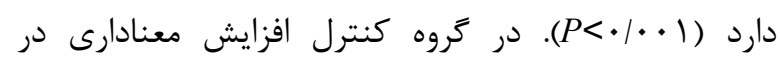

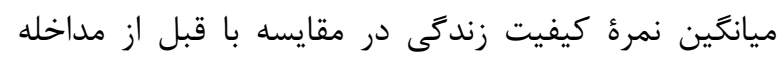

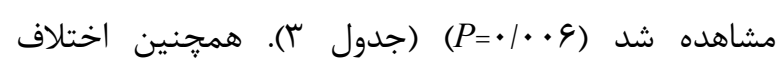

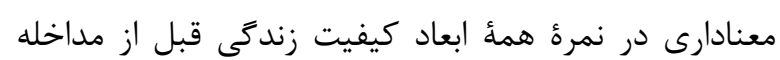

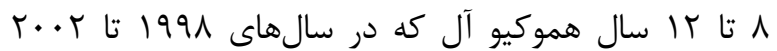

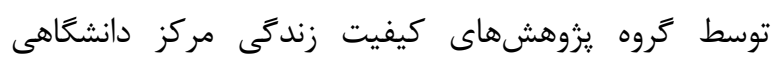

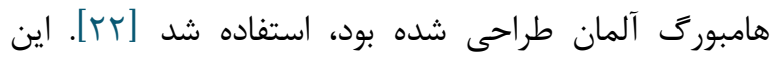

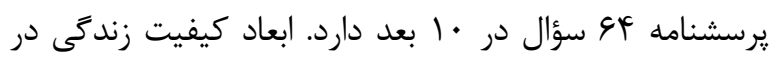

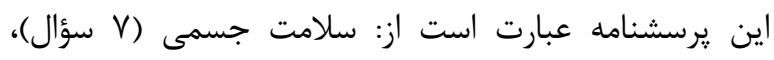

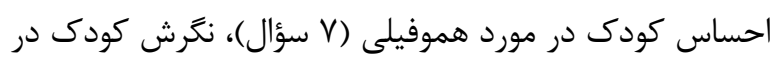

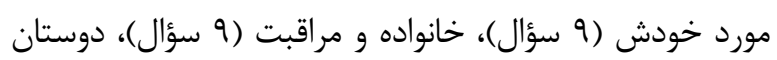

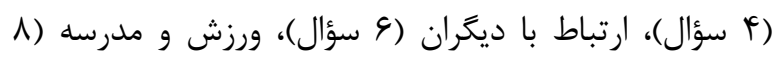

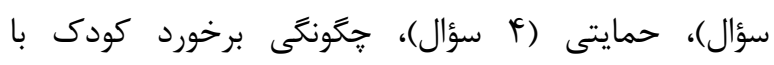

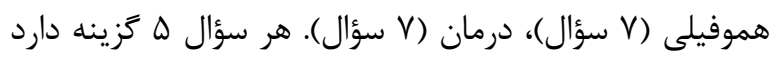

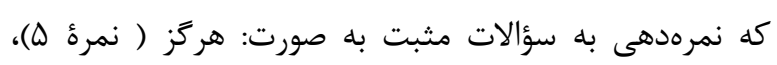

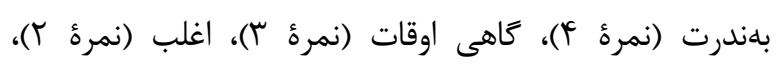

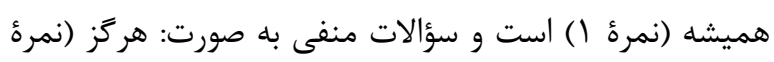

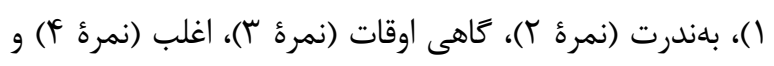

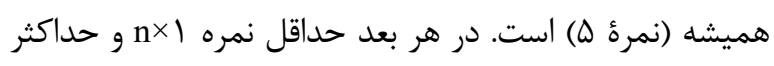

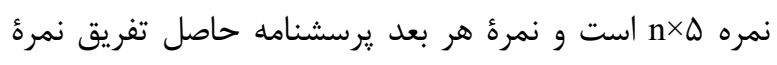

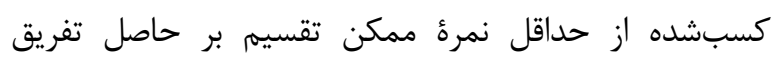

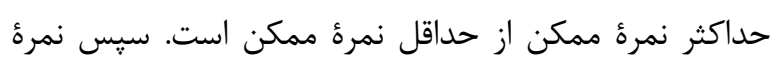

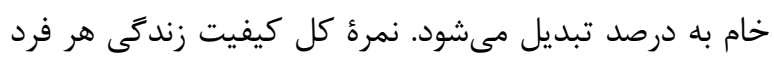

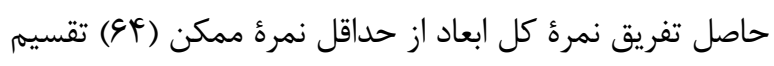

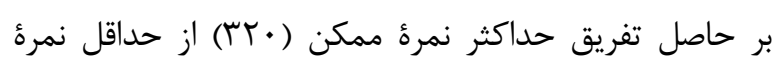

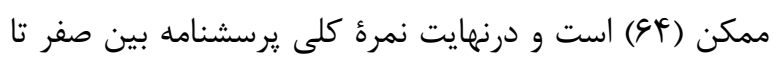

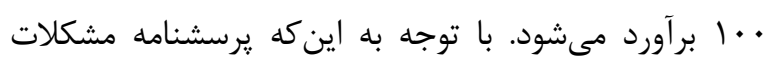

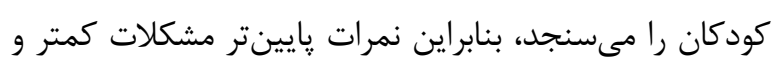

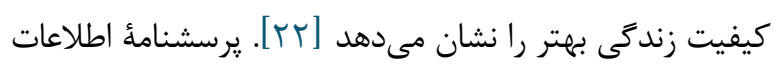

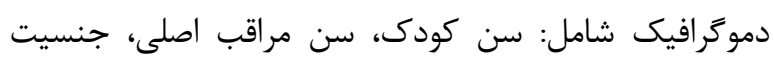

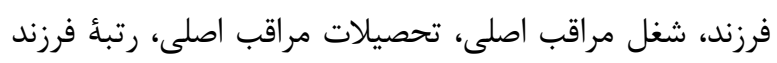

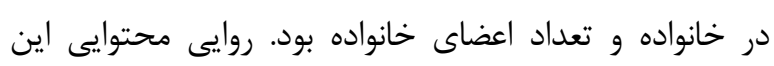
يرسشنامه توسط ها نفر از اعضاى هيئت علمى دانشكاه علوم

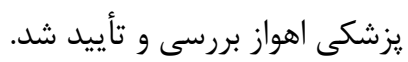

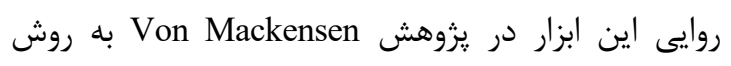

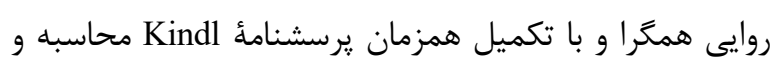

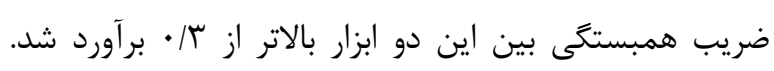

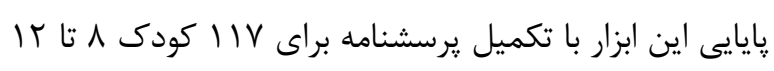

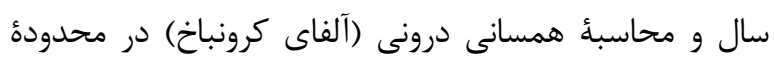

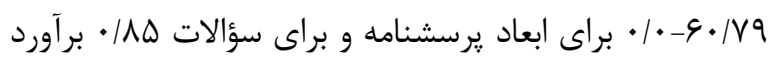

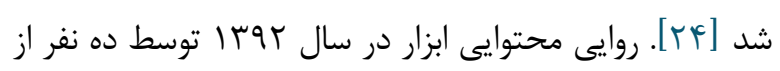

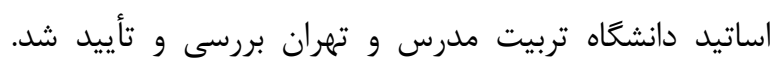


9 بررسى تأثير توانمندسازى خانوادهحور بر كيفيت زندگى كودكان مبتلا به هموفيلى

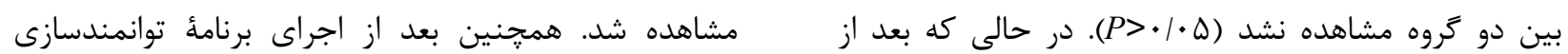

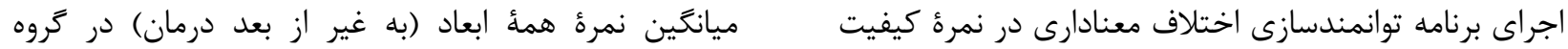

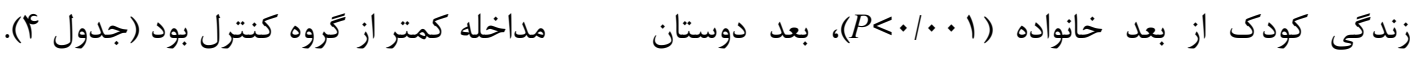

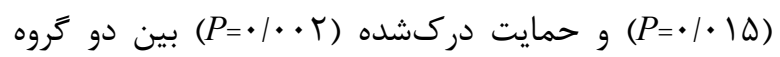

جدول ا. مقايسه فراوانى متغيرهاى دموكرافيك كيفى در تروههاى مداخله و كنترل

\begin{tabular}{|c|c|c|c|c|c|c|}
\hline & درصد & فراوانى & درصد & فراوانى & تروه & متغير \\
\hline \multirow{2}{*}{. ISTS } & $9 r$ & r & $\Lambda \Lambda$ & Tt & يسر & \multirow{2}{*}{ جنس كودى } \\
\hline & $\wedge$ & r & IT & r & دختر & \\
\hline \multirow{3}{*}{$\cdot / r \Delta q$} & r & 1 & . & . & بيكار & \multirow{3}{*}{ شغل يدر } \\
\hline & re & 9 & $\Delta \varphi$ & If & كارمند & \\
\hline & 4. & 10 & fr & 11 & شغل آزاد & \\
\hline \multirow{3}{*}{. $/ 941$} & $r$. & 1. & re & 9 & زير دييلم & \multirow{3}{*}{ تحصيلات يدر } \\
\hline & r. & 1. & $r$. & 1. & دييلم & \\
\hline & $r \cdot$ & $\Delta$ & rF & 4 & 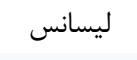 & \\
\hline \multirow{3}{*}{ - IDFF } & in & IT & $r$. & 1. & زير دييلم & \multirow{3}{*}{ تحصيلات مادر } \\
\hline & $\Delta T$ & Ir & $\Delta \varphi$ & If & دييله & \\
\hline & . & . & f & 1 & 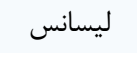 & \\
\hline \multirow[t]{2}{*}{ - /VSD } & $g t$ & 19 & 91 & IV & 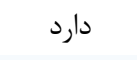 & \multirow{2}{*}{ نسبت فاميلى يدر و مادر } \\
\hline & re & 9 & rt & $\wedge$ & 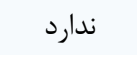 & \\
\hline \multirow{2}{*}{$\cdot 1 \cdot 19$} & r. & 1. & $q 4$ & 19 & دارد & \multirow{2}{*}{ سابقه بيمارى هموفيلى در خانواده } \\
\hline & 4. & 10 & re & 9 & 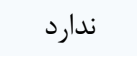 & \\
\hline \multirow{3}{*}{.194.} & Ve & 19 & st & 19 & ا مرتبه & \multirow{3}{*}{ دفعات غيبت از مدرسه } \\
\hline & $r \cdot$ & $\Delta$ & rᄉ & $\checkmark$ & 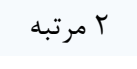 & \\
\hline & f & 1 & $\Lambda$ & r & T ب مرتبه > & \\
\hline \multirow{3}{*}{$\cdot|9 \Lambda|$} & $\Delta \varphi$ & if & 4. & 10 & $1-r$ & \multirow{3}{*}{ دفعات غيبت از مدرسه در ماه } \\
\hline & rᄉ & $\checkmark$ & rt & $\wedge$ & $r-r$ & \\
\hline & 19 & If & $\wedge$ & r & $\Delta-9$ & \\
\hline
\end{tabular}

جدول r. مقايسه ميانگين و انحراف معيار سن در تروه هاى مداخله و كنترل

\section{P-value}

$\cdot / 499$

.1919

I/TY
$1 \cdot 119$

انحر اف استاندارد

مداخله

كنترل

r

$1 \cdot 118$

$1 \cdot / 19$

\begin{tabular}{|c|c|c|c|}
\hline$=.1$ & \multicolumn{2}{|c|}{ مd احلم } & \multirow{2}{*}{ متغير } \\
\hline ميانغي & انحراف استاندارد & ميانگين & \\
\hline $4 / 9 \Lambda$ & $r / 9 r$ & $r \Delta / v T$ & سن مراقبين \\
\hline & $1 / F T$ & $1 . / 1 T$ & ن كودكان \\
\hline
\end{tabular}




$$
\text { شهناز رستمى و همكاران }
$$

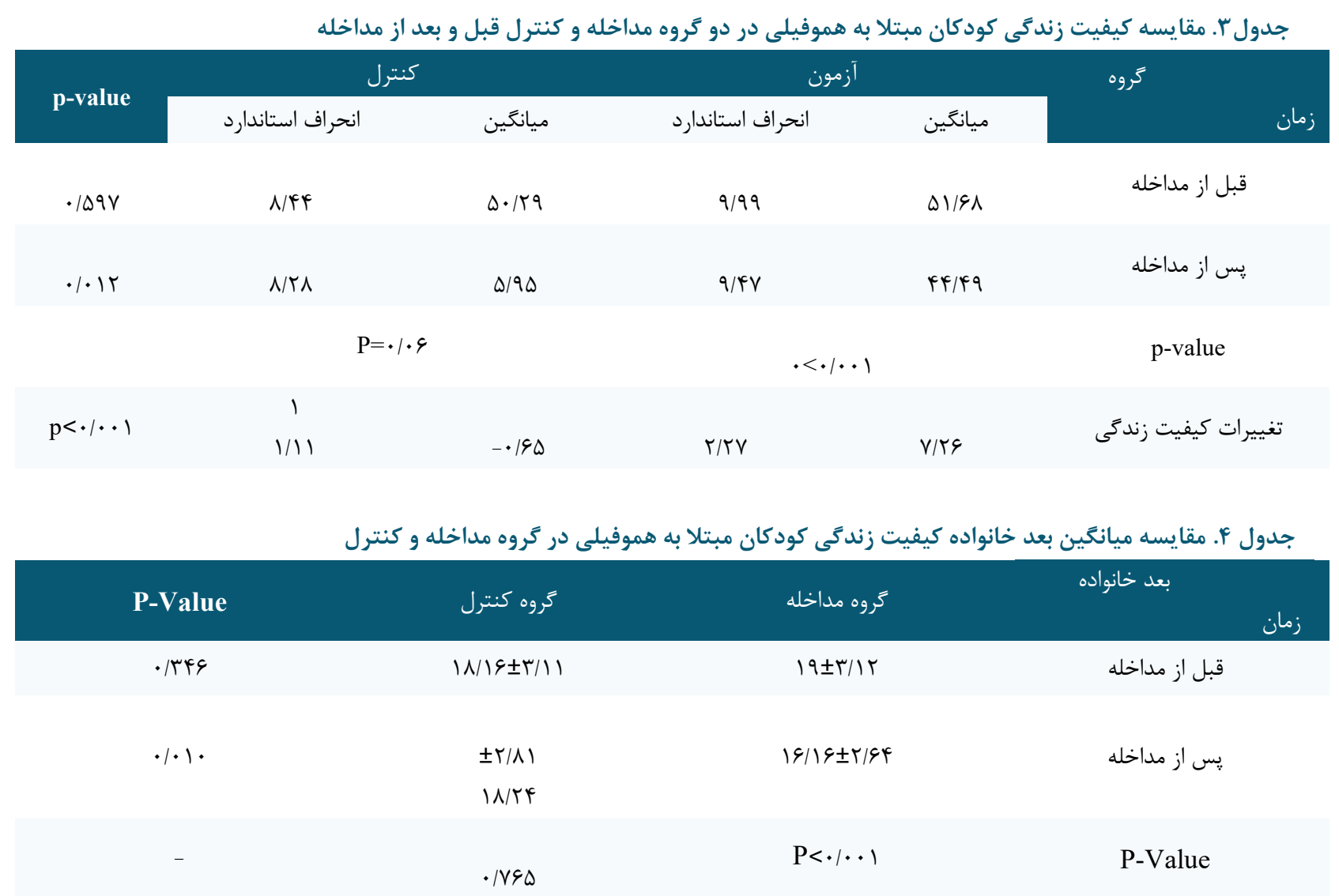

جدول Fا. مقايسه ميانعين بعد دوستان كيفيت زندكَى كودكان مبتلا به هموفيلى در كروه مداخله و كنترل

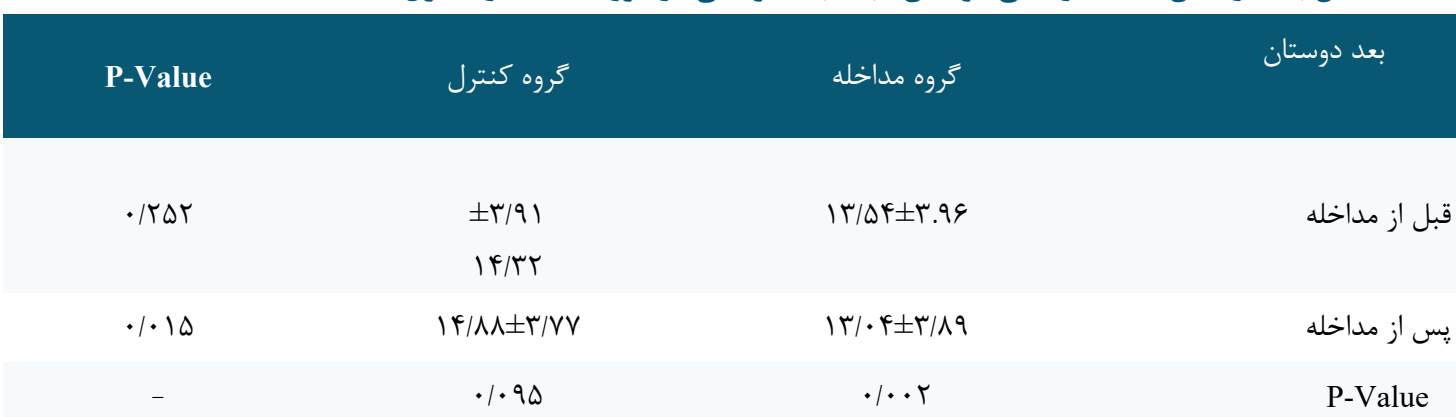

جدول F. مقايسه ميانكين بعد حمايت درك شده كيفيت زندكى كودكان مبتلا به هموفيلى در كروه مداخله و كنترل

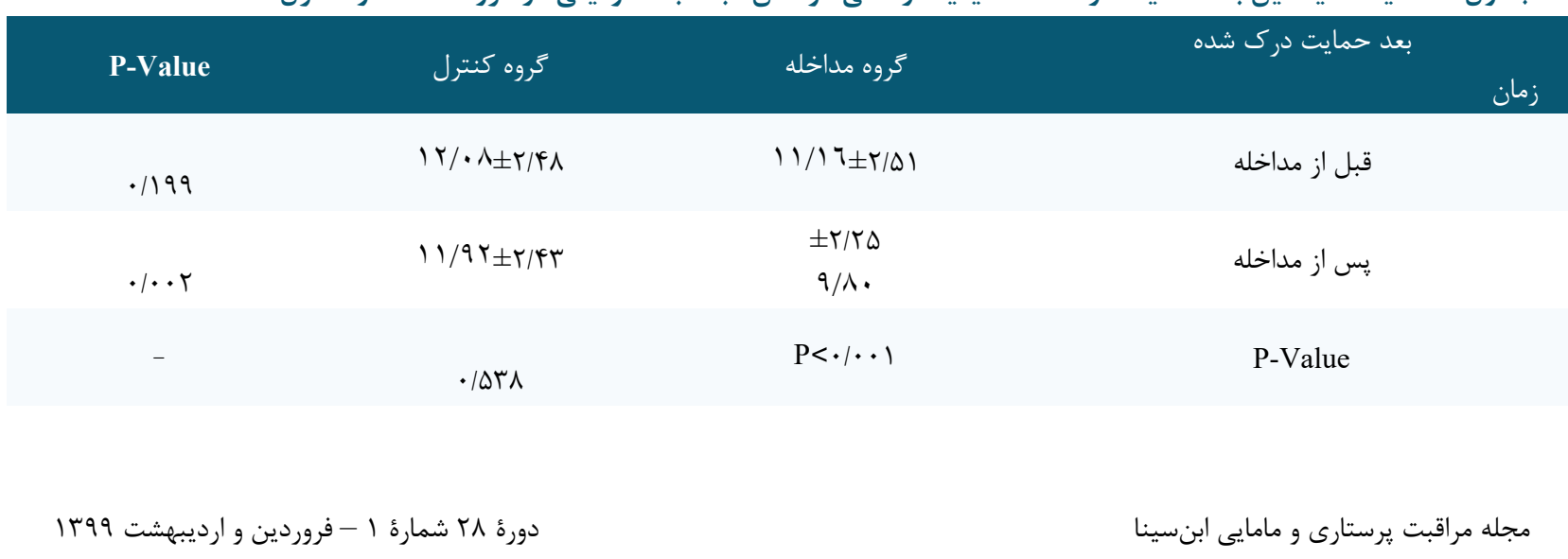


كيفيت زندگى زنان مبتلا به سرطان پِتان را در گروه

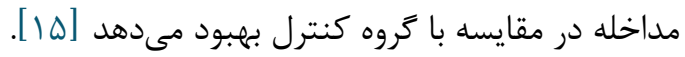

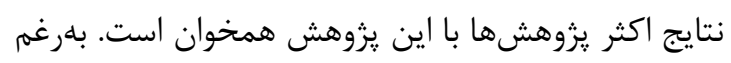
اين كه نوع جامعه و نوع بيمارى متفاوت است، اما مىتوان

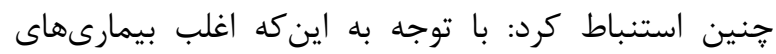

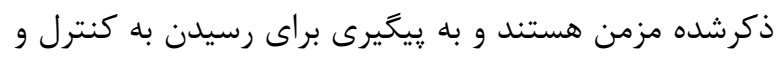

درمان بيمارى نياز دارند، لذا شرايط تقريبا يكسانى دارند.

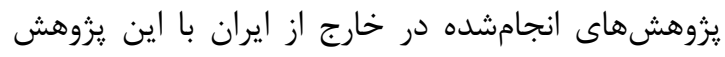

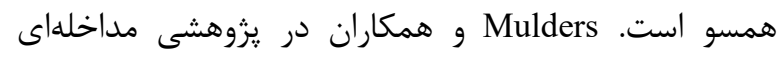

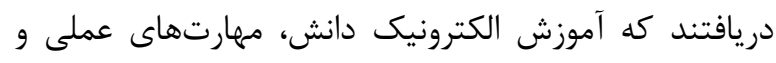

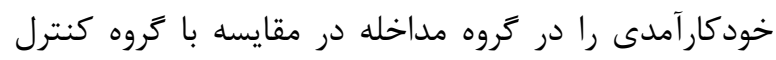

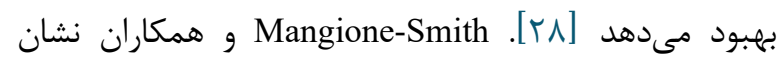

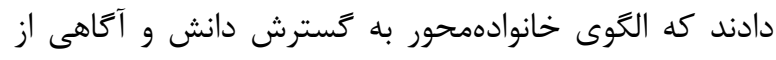

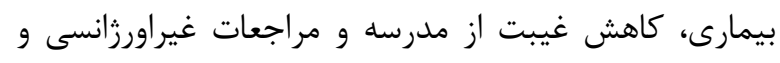

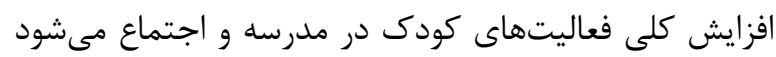

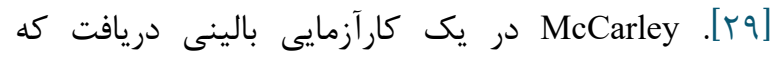

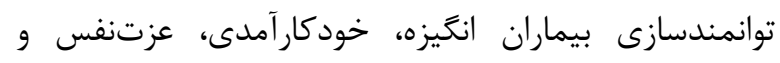

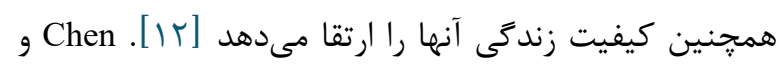

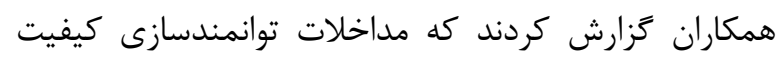

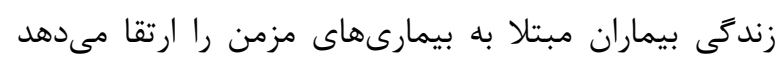

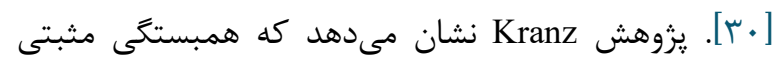
بين توانمندسازى خانوادهمحور با كيفيت زندانى مانى سالمندان

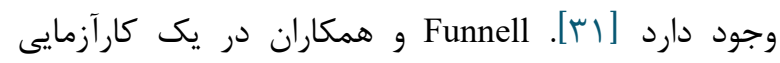

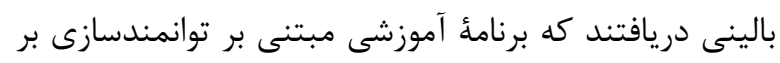

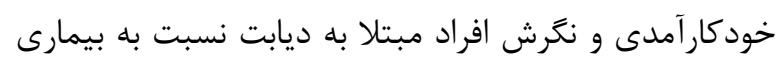

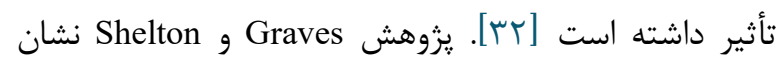

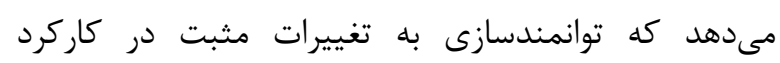

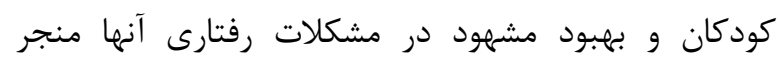
مىشود [بr]. - مكان. كَامهاى خاص الكَى توانمندسازى به به دركير شدن

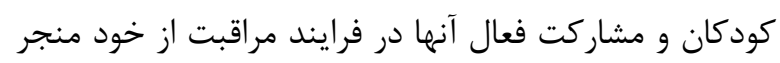

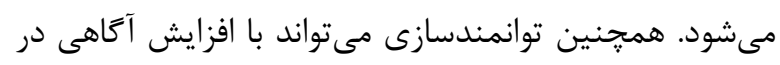

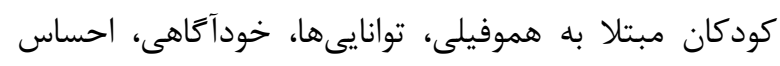

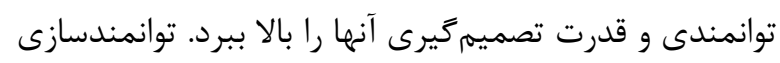

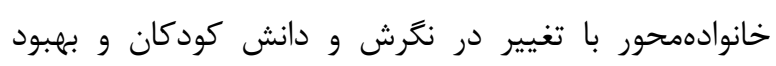

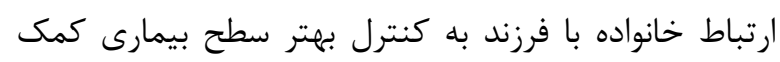

اين يزوهش تأثير توانمندسازى خانوادهمحور را بر كيفيت

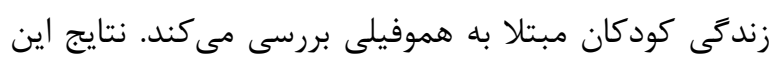

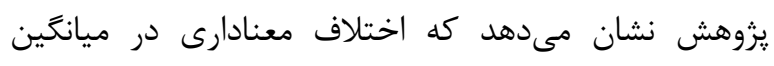

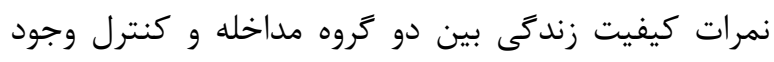

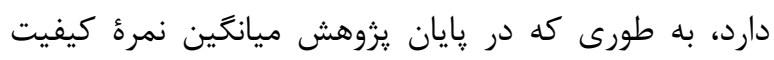

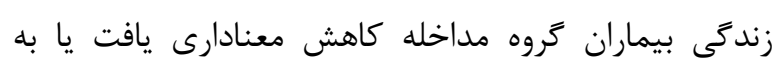

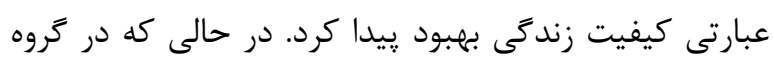

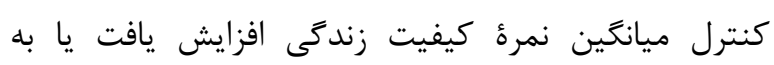

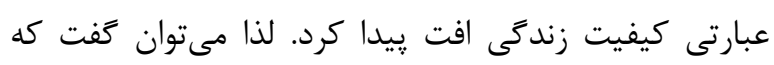

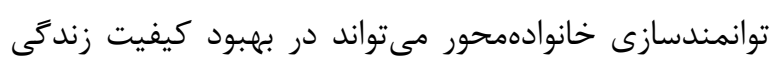

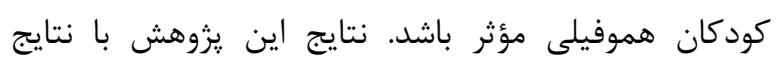

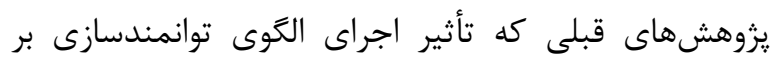

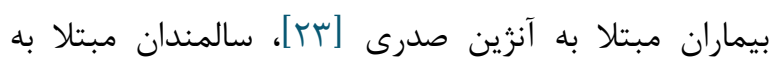

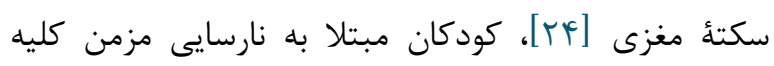

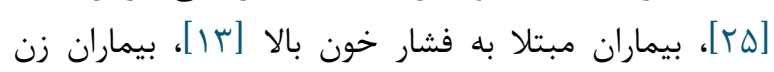

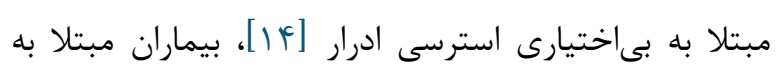
ديابت نوع r [ع| ] را بررسى كردهاند، همسو است.

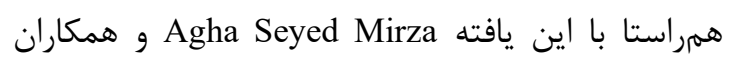

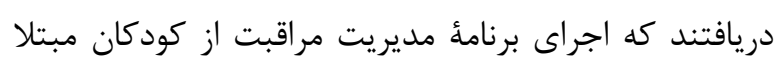

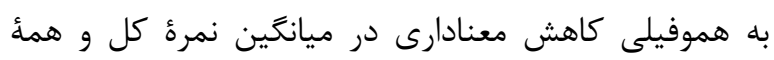

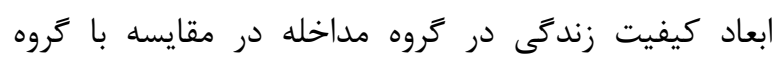

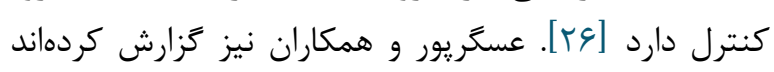

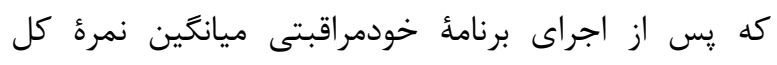

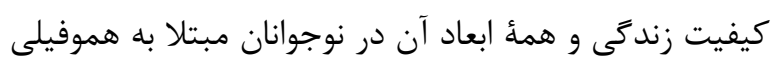

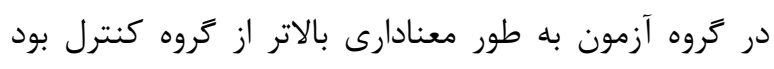

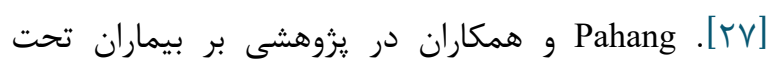

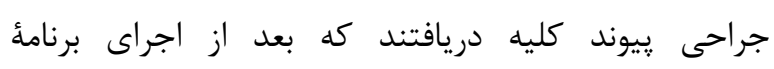

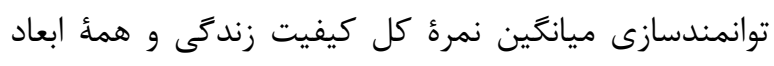

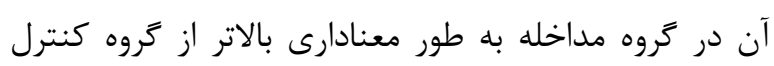

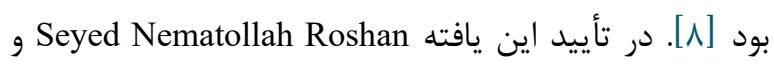

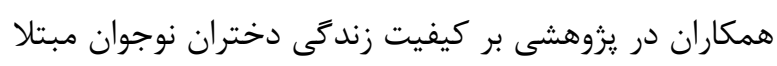

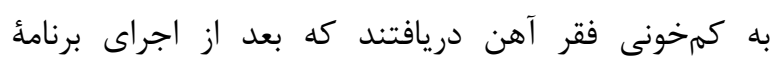

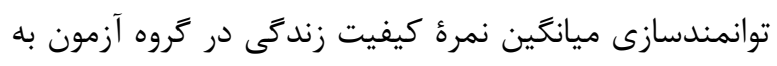

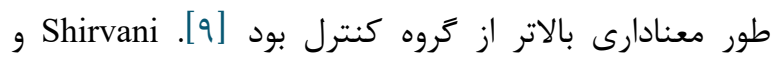

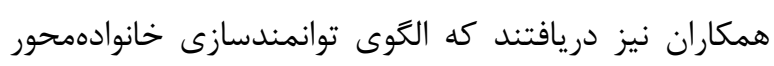




$$
\begin{aligned}
& \text { سياسگزןارى } \\
& \text { اين طرح در كميتهُ اخلاق در يزوهش دانشعاه علوم } \\
& \text { يزشكى اهواز با كد اخلاق IR.AJUMS.REC.1397.571 و ولرين } \\
& \text { كد طرح Th-9710 تصويب شده است. بدين وسيله از معاونت } \\
& \text { يزوهشى دانشعاه علوم يزشكى اهواز و بيمارانى كه در اجراى } \\
& \text { اين يزوهش با ما همكارى كردهاند، تشكر مى كنيم. } \\
& \text { تعارض در منافع } \\
& \text { بين نويسندكان هيجزَّه تعارضى در منافع وجود ندارد } \\
& \text { منابع مالى } \\
& \text { منابع مالى اين مطالعه توسط نويسند }
\end{aligned}
$$

\section{References}

1. Mojen LK. Comparison of quality of life between hemophilic children receiving. Advances in Nursing \& Midwifery. 2013;22(77):39-45.[doi: org/10.22037/anm.v22i77.4100 ]

2. Zafar ramzanian Z, Alhani F, Anoosheh M. The effect of Family Centered Empowerment Model on mothers' QOL of girls under six years old with UTI . JHPM. 2014; 3 (3) :7-15

3. Alhani F, Niknami S, Kimiagar M, Kazemnezhad A, Heidarni A. Design and evaluation of the familyoriented prevention of iron deficiency Anemia. Tehran: Tarbiyat Modarres University. 2003;8:283-9.

4. Mercan A, Sarper N, Inanır M, Mercan HI, Zengin E, Kılıç SÇ, et al. Hemophilia-Specific Quality of Life Index (Haemo-QoL and Haem-A-QoL questionnaires) of children and adults: result of a single center from Turkey. Pediatric hematology and oncology. 2010;27(6):449-61. [DOI:10.3109/08880018.2010.489933] [PMID]

5. Von Mackensen S, Bullinger M, Group HQ. Development and testing of an instrument to assess the Quality of Life of Children with Haemophilia in Europe (Haemo-QoL). Haemophilia. 2004;10:17-25. [DOI:10.1111/j.1355-0691.2004.00875.x] [PMID]

6. Agha Seyed Mirza SS, Memarian R, Vanaki Z. The evaluation of effect case management program on quality of life of pre-school children with hemophilia. Quarterly Journal of Nursing Management. 2013 Jun 10;2(1):38-47.

7. Asgarpour H, Mohammadi E, Memarian R. The effect of self care program on the quality of life of adolescents with hemophilia. Daneshvare Pezeshki Journal. 2008;14(69):1-8.

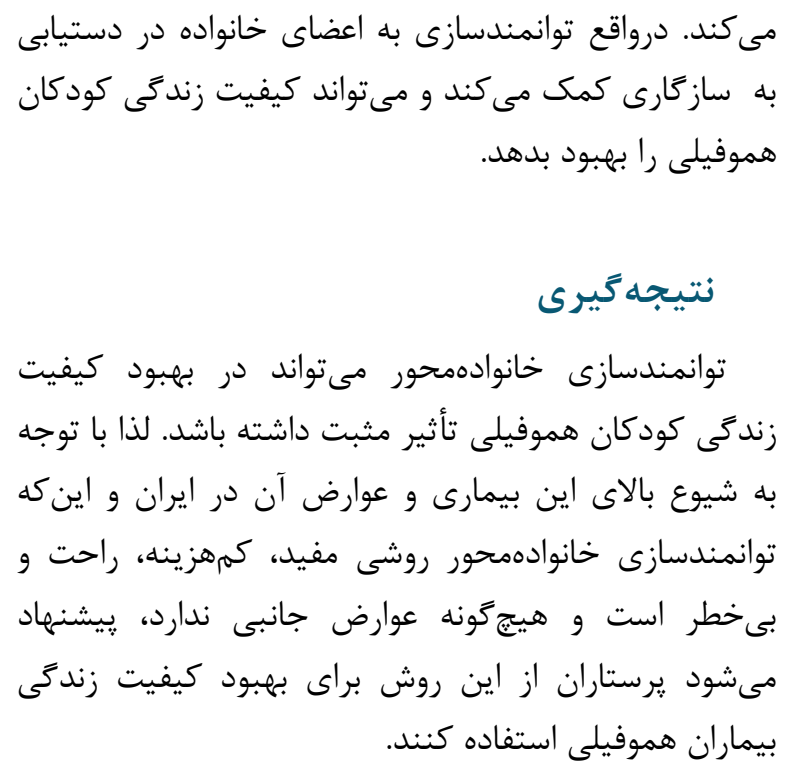

8. Pahang S, Abkhiz S, Hemmati Maslak Pak M, Khalkhali HR. The Effect Of The Implementation Of Family-Centered Empowerment Model On The Quality Of Life For Kidney Transplant Patients. The J Urmia Nurs Midwifery Fac. 2018;15(10):724-32.

9. Seyed Nematollah Roshan F, Navipor H, Alhani F. Effect of Family-Centered Empowerment Model (FCEM) on quality of life of mothers having teenagers with iron deficiency anemia. Journal of Nursing Education. 2014;3(2):27-40.

10. Farzami HA, Heravi-Karimooi M, Rejeh N, Alhani F, Sharif Nia H. The effect of family-centered empowerment model on quality of life in elderly patients with angina. Payesh. 2017; 16 (6) :775-783

11. Broderick CR, Herbert RD, Latimer J, Curtin JA, Selvadurai HC. The effect of an exercise intervention on aerobic fitness, strength and quality of life in children with haemophilia (ACTRN012605000224628 .[DOI:10.1186/14712326-6-2].

12. Minooei MS, Ghazavi Z, Abdeyazdan Z, Gheissari A, Hemati Z. The Effect of the Family Empowerment Model on Quality of Life in Children with Chronic Renal Failure: Children's and Parents' Views. Nephro-urology monthly. 2016;8(4). [DOI:10.5812/numonthly.36854] [PMID] [PMCID]

13. Noori R, Alami A, Delshad Noghabi A. Effect of family-centered empowerment model on quality of life in patients with hypertension. Journal of Mazandaran University of Medical Sciences. 2015;25(127):100-7. 


$$
\text { • ا بررسى تأثير توانمندسازى خانوادهمحور بر كيفيت زندگى كودكان مبتلا به هموفيلى }
$$

14. Sh K, Kolbadinezhad N, Alami A, Sh T. Effect of intervention based on family-centered empowerment model on the quality of life of women suffering from stress urinary incontinence. Quarterly of the Horizon sciences. 2014;19(5):271-80.

15. Shirvani H, Alhani F, Montazeri A. The effect of Family-centered Empowerment Model on the Functional Scales Quality of Life in Women with Breast Cancer Undergoing Chemotherapy. 2017;10(1):61-72.

16. Ghotbi N, Seyed Bagher Maddah S, Dalvandi A, Arsalani N, Farzi M. The effect of education of self care behaviors based on family-centered empowerment model in type II diabetes. Journal of Nursing and Midwifery Quarterly-Shaheed Beheshti University of Medical Sciences and Health Services. 2014;23(83):43-50.

17. Nazari S SKM AGF. Survey of Parents' Knowledge Regarding Their Children's Genetic Diseases. Genetics in the 3rd Millennium 2011. 2007;9(1)::2285-9.

18. Teymouri F, Alhani F, Kazemnejad A. The effect of the family-centered empowerment model on the quality of life in parents of children with asthma. avicenna Journal Of Nursing And Midwifery Care . 2014; 22(3); 5-14

19. Hakim A, Palizban E, Ahmadi Angali K. The effect of family-centered empowerment model on the Level of parents' knowledge of children with ostomy. Journal of Pediatric Nursing. 2015;1(4):22-31.

20. Nachshen J, Minnes P. Empowerment in parents of school-aged children with and without developmental disabilities. Journal of Intellectual Disability Research. 2005;49(12):889-904.

21. Dunst CJ, Trivette CM. Meta-analytic structural equation modeling of the influences of familycentered care on parent and child psychological health. International journal of pediatrics. 2009;2009.

22. Mercan A, Sarper N, Inanır M, Mercan HI, Zengin E, Kılıç SC, Gökalp AS. Hemophilia-Specific Quality of Life Index (Haemo-QoL and Haem-A-QoL questionnaires) of children and adults: result of a single center from Turkey. Pediatric hematology and oncology. 2010 Aug 27;27(6):449-61.

23. Farzami HA, Heravi-Karimooi M, Rejeh N, Alhani F, Nia HS. The effect of family-centered empowerment model on quality of life in elderly patients with angina. Payesh (Health Monitor). 2017 15;16(6):775-83.

24. Deyhoul N, Vasli P, Rohani C, Shakeri N, Hosseini M. The effect of family-centered empowerment program on the family caregiver burden and the activities of daily living of Iranian patients with stroke: a randomized controlled trial study. Aging clinical and experimental research. 2019 Aug 31:1-0. [DOI:10.1007/s40520-019-01321-4].

25. Minooei MS, Ghazavi Z, Abdeyazdan Z, Gheissari A, Hemati $Z$. The effect of the family empowerment model on quality of life in children with chronic renal failure: Children's and parents' views. Nephrourology monthly. 2016; 8(4). [Doi: 10.5812/numonthly.36854].

26. Agha Seyed Mirza SS, Memarian R, Vanaki Z. The evaluation of effect case management program on quality of life of pre-school children with hemophilia. Quarterly Journal of Nursing Management. 2013 10;2(1):38-47.

27. Asgarpour H, Mohammadi E Memaran R. The effect of self care program on the quality of life of adolescents with hemophilia. Daneshvare Pezeshki Journal. 2008;14(69):1-8

28. Mulders G, De Wee E, Vahedi Nikbakht-Van de Sande M, Kruip M, Elfrink E, Leebeek F. E-learning improves knowledge and practical skills in haemophilia patients on home treatment: a randomized controlled trial. Haemophilia. 2012;18(5):693-8. [DOI:10.1111/j.13652516.2012.02786.x] [PMID]

29. Mangione-Smith R, Schiff J, Dougherty D. Identifying children's health care quality measures for Medicaid and CHIP: an evidence-informed, publicly transparent expert process. Academic Pediatrics. 2011;11(3):S11-S21.

[DOI:10.1016/j.acap.2010.11.003] [PMID

30. Chen Y-C, Li I-C. Effectiveness of interventions using empowerment concept for patients with chronic disease: a systematic review. JBI Database of Systematic Reviews and Implementation Reports. 2009;7(27):1179-233. [DOI:10.11124/01938924200907270-00001] [PMID]

31. Kranz K. The Relationship Between Empowerment Care and Quality of Life Among Members of Assisted Living Facilities. Journal of Undergraduate Research, XIV. 2011:1-5.

32. Funnell MM, Anderson RM. Patient empowerment: a look back, a look ahead. The Diabetes Educator. 2003;29(3):454-64.

[DOI:10.1177/014572170302900310] [PMID]

33. Graves KN, Shelton TL. Family empowerment as a mediator between family-centered systems of care and changes in child functioning: Identifying an important mechanism of change. Journal of Child and Family Studies. 2007;16(4):556-66. [DOI:10.1007/s10826-006-9106-1] 